\title{
Construction and verification of CYP3A5 gene polymorphisms using a Saccharomyces cerevisiae expression system to predict drug metabolism
}

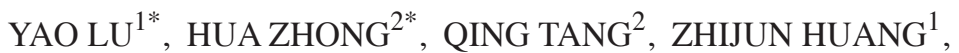 \\ NINGNING JING ${ }^{2}$, JULIE SMITH ${ }^{3}$, RUJIA MIAO ${ }^{1}$, YAPEI LI $^{1}$ and HONG YUAN ${ }^{1}$
}

Departments of ${ }^{1}$ Clinical Pharmacy and ${ }^{2}$ Cardiology, The Third Xiangya Hospital, Central South University, Changsha, Hunan 410013, P.R. China; ${ }^{3}$ School of Community Health Sciences, University of Nevada, Reno, NV 89557, USA

Received September 14, 2016; Accepted January 5, 2017

DOI: $10.3892 / \mathrm{mmr} .2017 .6214$

\begin{abstract}
The present study evaluated the ability of a Saccharomyces cerevisiae expression system to predict the pharmacokinetic (PK) activity of a calcium channel blocker in patients with distinct cytochrome P450 3A5 (CYP3A5) polymorphisms. The blood pressure lowering activity of amlodipine in 57 hypertensive patients with $C Y P 3 A 5^{*} 1 /^{*} 1$, $C Y P 3 A 5^{*} 1 /^{*} 3, C Y P 3 A 5^{*} 4$ and $C Y P 3 A 5^{*} 6$ polymorphisms was evaluated by the current study. Subsequently, a Saccharomyces cerevisiae expression system for CYP3A5 gene polymorphisms was constructed to examine the PK activity of $C Y P 3 A 5^{*} 1 /^{*} 1, C Y P 3 A 5^{*} 4$ and $C Y P 3 A 5^{*} 6$ polymorphisms. This system was used to predict the PK of amlodipine and was compared with the in vivo data from different gene polymorphism groups. The blood pressure lowering activity of amlodipine in hypertensive patients varied among CYP3A5 polymorphisms. The in vivo results demonstrated that $C Y P 3 A 5^{*} 6$ exhibited the highest metabolic rate, followed by $C Y P 3 A 5^{*} 1 / /^{*} 1, C Y P 3 A 5^{*} 4$ and $C Y P 3 A 5^{*} 1 /^{*} 3$. The difference between $C Y P 3 A 5^{*} 6$ and $C Y P 3 A 5^{*} 1 /^{*} 1$ was not statistically significant $(\mathrm{P}=0.5)$. In accordance with in vivo data, CYP $3 A 5^{*} 1 /^{*} 1$ exhibited the highest in vitro metabolic rate, followed by $C Y P 3 A 5^{*} 6$ and $C Y P 3 A 5^{*} 4$. With the exception of the comparison between $C Y P 3 A 5^{*} 6$ and $C Y P 3 A 5^{*} 1 / /^{*} 1$, polymorphisms exhibited statistically significant differences compared with $C Y P 3 A 5^{*} 1 /^{*} 1(\mathrm{P}<0.05)$. The Saccharomyces cerevisiae expression system may be a
\end{abstract}

Correspondence to: Dr Hong Yuan, Department of Clinical Pharmacy, The Third Xiangya Hospital, Central South University, 138 Tong Zi Po Road, Changsha, Hunan 410013, P.R. China

E-mail: yuanhong01@vip.sina.com

*Contributed equally

Key words: drug metabolism, cytochrome P450 3A5, gene polymorphism, pharmacokinetic, pharmacodynamics cost effective and potentially useful tool for assessing the PK activity of drugs that are metabolized by $C Y P 3 A 5$.

\section{Introduction}

Cytochrome $\mathrm{P} 450$ (CYP) are a family of hemoproteins involved in multiple enzymatic reactions, such as drug metabolism. Previous studies have indicated that gene polymorphisms may be a major cause of the variability in drug metabolism that exists among individuals. The $C Y P 3 A$ subfamilies are the most abundant $C Y P s$ in the human liver and intestine. $C Y P 3 A$ catalyzes the metabolism of drugs, and contributes to variations in the bioavailability and clearance of $C Y P A 3$ substrates (1-4). $C Y P 3 A 4$ is the most abundant hepatic and intestinal $C Y P 3 A$ isoform. Researchers previously thought that $C Y P 3 A 4$ was the primary contributor to metabolism within this family, however, this view was recently challenged by data that indicated that the relative contribution of $C Y P 3 A 5$ may represent $>50 \%$ of total $C Y P 3 A$ in certain individuals and may exert a greater metabolic action than previously considered in individuals that possess at least one polymorphic $C Y P 3 A 5$ allele $(3,5,6)$. The wild type allele of $C Y P 3 A 5$ is defined as $C Y P 3 A 5^{*} 1$. Mutations include the following: $C Y P 3 A 5^{*} 2 ; C Y P 3 A 5^{*} 3 A ; C Y P 3 A 5^{*} 3 C$; CYP3A5*4; CYP3A5*5; CYP3A5 6; and CYP3A5*7. The penetrance of polymorphic $C Y P 3 A 5$ genotypes varies among different ethnic groups and polymorphic CYP3A5 genotypes have varying pharmacokinetics $(\mathrm{PK})$ and pharmacodynamics (PD) among $C Y P 3 A$ substrates, which include the calcium channel blocker, amlodipine $(7,8)$. The effects of amlodipine vary depending on which $C Y P 3 A 5$ allele an individual has. For example, among Korean and Chinese patients that were treated with amlodipine, homozygous $C Y P 3 A 5^{*} 3$ carriers $(2,9)$ exhibited a greater oral clearance of amlodipine and reduced mean area under the plasma concentration-time curve compared with $C Y P 3 A 5^{*} 1$ carriers (10-12). Additionally, Zhang et al (2) demonstrated that $C Y P 3 A 5^{*} 3 /^{*} 3$ patients exhibited lower plasma levels of amlodipine compared with $C Y P 3 A 5^{*} 1$ patients, which indicated that patients with polymorphisms may have faster amlodipine metabolism and increased $C Y P 3 A$ enzyme activity (2). This heterogeneity in enzyme action indicates the requirement for a reliable method to assess the impact 
of polymorphisms in amlodipine metabolism. To investigate the impact of CYP3A5 genetic polymorphisms on amlodipine metabolism, the present study enrolled 57 Chinese hypertensive patients with four different polymorphisms: $C Y P 3 A 5^{*} 1 I^{*} 1$ $(\mathrm{n}=7) ; C Y P 3 A 5^{*} 1 /^{*} 3(\mathrm{n}=28) ; C Y P 3 A 5^{*} 4(\mathrm{n}=2)$; and $C Y P 3 A 5^{*} 6$ $(\mathrm{n}=2)$. Changes in the blood pressure of patients following administration of amlodipine were recorded. In addition, a well-investigated and cost-effective Saccharomyces cerevisiae expression system was constructed to validate the results obtained in the in vivo assessment.

\section{Materials and methods}

Patients and study design. The study protocol and consent for prospectively enrolled patients were approved by the Ethics Committee of the Third Xiangya Hospital (Changsha, China). Informed consent was obtained from all individual participants included in the study. The study included 57 hypertensive patients that were assigned to receive amlodipine from a single center in China between May 2012 and February 2013. Patients were included in the study if they were between the ages of 18 and 70, and diagnosed with a systolic blood pressure $\geq 140 \mathrm{mmHg}$ or a diastolic blood pressure $\geq 90 \mathrm{mmHg}$. Patients were excluded if they exhibited any of the following complications: Cerebrovascular accident history, heart failure, serious organic heart disease, large aneurysm and aortic dissection, second degree atrioventricular block, sick sinus syndrome, arrhythmia of clinical significance, ventricular tachycardia, atrial fibrillation or flutter, untreated thyroid disease, gastrointestinal lesions or prior gastrointestinal surgeries that may affect drug absorption, history of malignancy or any liver, kidney, heart and lung function congruent with a life-threatening illness, liver dysfunction, allergy to amlodipine, pregnancy or lactation, mental illness, active use of other antihypertensive drugs during the trial period or participating in other clinical trials within 3 months of enrolling in the current study. The suitability of all subjects was determined using medical history, routine physical examinations, clinical laboratory testing, and measuring the heart rate and blood pressure. Following a 1-week washout period, baseline blood pressure values were recorded. All subjects received a single oral dose of $5 \mathrm{mg}$ /day amlodipine (one $5 \mathrm{mg}$ tablet; Pfizer Inc., New York, NY, USA) with water (200 ml) in the morning for 4 weeks. A series of $5 \mathrm{ml}$ venous blood samples were collected into heparinized tubes from the antecubital vein of patients. Aliquots of plasma $(2 \mathrm{ml})$ isolated from the blood were stored at $-80^{\circ} \mathrm{C}$ until analysis. The blood samples were collected at $0,24,48,72$ and $120 \mathrm{~h}$, and the plasma concentrations of amlodipine were measured through 4 weeks following the blood sample collection. The blood pressure of patients was measured with the calibrated Electronic Blood Pressure Monitor (HEM-7012; Omron Corporation, Kyoto, Japan) at $0 \mathrm{~h}$ on days 0 and 28 of drug treatment. DNA was extracted from patient peripheral blood samples prior to the treatment. Genotypes for the CYP3A5 polymorphisms were determined by polymerase chain reaction (PCR)-restriction fragment length polymorphism as previously described (13). Blood drug concentrations of each CYP3A5 genotype group was measured with liquid chromatography-mass spectrometry (LC-MS) $(14,15)$ and high performance liquid chromatography
(HPLC) (16). The metabolic rate of amlodipine was calculated in each group.

Construction of CYP3A5 gene polymorphism expression vectors. The pYES2/CT vector was purchased from Invitrogen (Thermo Fisher Scientific, Inc.). All primers used in this study are presented in Table I (Shenzhen Huada Gene Science and Technology Co., Ltd., Shenzhen, China) (5). The total CYP3A5 RNA was extracted from human liver cells (collected from a 33 year old male patient who had undergone surgery and signed the informed consent) following the Qiagen RNeasy Mini Kit (Qiagen, GmbH, Hilden, Germany) protocol. The tissue sections were homogenized in RLT buffer supplemented with $2 \mathrm{M}$ dithiothreitol using a $1 \mathrm{ml}$ syringe and a needle. Homogenized cells were applied to an RNeasy spin column, washed, and then eluted in $50 \mathrm{ml}$ of water and stored at $-20^{\circ} \mathrm{C}$ until required. cDNA was obtained via RNA reverse transcription using a reverse transcription kit (Qiagen, $\mathrm{GmbH}$ ) according to the manufacture's protocol. cDNA fragments were amplified using PCR as presented in Tables II and III, according to the manufacturer's protocol.

The CYP3A5-CDS-F/CYP3A5-CDS-R primers are presented in Table I, and GAPDH served as a control. Gel electrophoresis products of PCR were analyzed using agarose gel electrophoresis. Agarose gels of 2\% (w/v) concentration were made in 0.5 Tris/Borate/EDTA buffer. Loading dye was added to the PCR products prior to being run at $120 \mathrm{~V}$ for 90 min alongside Hyperladder II (Bioline UK, London England) for comparison. Ethidium bromide at a concentration of $0.5 \mathrm{mg} / \mathrm{ml}$ (CLP, US) was used to stain the DNA for visualization using a UV transilluminator. RT-PCR products were alternatively analyzed using a standard procedure on a Capillary Gel Electrophoresis CEQ 8000 Genetic Analyser (Beckman Coulter, Inc., Brea, CA, USA).

The human liver cells were cultured in Dulbecco's modified Eagle's medium (Invitrogen, Thermo Fisher Scientific, Inc.) supplemented with $20 \%$ fetal bovine serum at a temperature of $37^{\circ} \mathrm{C}$ in an environment containing $5 \% \mathrm{CO}_{2}$. PCR products of the cDNA fragments (Table I) were purified and ligated into the pMD18-T simple vector (Invitrogen; Thermo Fisher Scientific, Inc.). The resulting pMD18-T-CYP3A5 plasmid was transformed into E. coli JM109 (Auragene Bioscience Corporation Inc, Changsha, China). The E. coli strains carrying the recombinant pMD18-T-CYP3A5 plasmid were cultured on LB agar supplemented with $50 \mu \mathrm{g} / \mathrm{ml}$ ampicillin at $37^{\circ} \mathrm{C}$ overnight. A single colony was transferred into $5 \mathrm{ml}$ of LB medium with ampicillin at the same concentrations used in the solid medium. The culture was incubated overnight at $37^{\circ} \mathrm{C}$ and $210 \mathrm{rpm}$. Subsequently, plasmids were extracted. Plasmids were double-enzyme digested with Hind III and Xho I (Thermo Fisher Scientific. Inc.), and the target gene fragments were inserted into the pYES2/CT plasmid that was digested with the same endonuclease enzyme, and the resultant recombinant plasmids were transformed into E. coli JM109 using the CYP3A5 expression vector and cultured E. coli JM109 at a temperature of $37^{\circ} \mathrm{C}$ and a revolution of $210 \mathrm{rpm} / \mathrm{min}$ in a medium containing $50 \mu \mathrm{g} / \mathrm{ml}$ ampicillin (17). Positive clones were screened for and the recombinant plasmid, CYP3A5-pYES2/CT, was extracted. CYP3A5*4 and CYP3A5*6 mutational expression vectors were constructed 
Table I. Primers used to construct the $C Y P 3 A 5$ gene polymorphism expression vectors in this study.

\begin{tabular}{ll}
\hline Primer & \multicolumn{1}{c}{ Primer sequence $\left(5^{\prime}-3^{\prime}\right)$} \\
\hline CYP3A5 & F: aagcttATGGACCTCATCCCAAAT $($ Hind III) \\
& R: ctcgagTTCTCCACTTAGGGTTCC $($ Xho I) \\
CYP3A5*4 & F: ATCCACGAGACCCCTTTGTGGAGAG \\
& CAC \\
& R: AGGGGTCTCGTGGATTGTTGAGAGA \\
& GTC \\
CYP3A5*6 & F: CACTAAAAAGTTCCTAAAATTTGGTT \\
& TCT \\
& R: GAACTTTTTAGTGCTCTCCACAAAGG \\
& GGT
\end{tabular}

CYP3A5, cytochrome P450 3A5; F, forward; R, reverse. The lower case letters represent the restriction sites.

Table II. Polymerase chain reaction system.

\begin{tabular}{lc}
\hline Reagents & volume $(\mu \mathrm{l})$ \\
\hline 10x LAmp buffer & 2.5 \\
dNTP & 2 \\
5x C solution & 5 \\
CYP3A5-CDS-F (10 uM) & 1 \\
CYP3A5-CDS-R (10 uM) & 1 \\
Template & 1 \\
Lamp DNA polymerase & 0.25 \\
ddH ${ }_{2} \mathrm{O}$ & Up to 25 \\
\hline
\end{tabular}

Table III. Polymerase chain reaction condition.

\begin{tabular}{lcc}
\hline Temperature $\left({ }^{\circ} \mathrm{C}\right)$ & Time \\
\hline 94 & $4 \mathrm{~min}$ & \\
94 & $30 \mathrm{sec}$ & 35 cycles \\
56 & $30 \mathrm{sec}$ & \\
72 & $1.30 \mathrm{~min}$ & \\
72 & $5 \mathrm{~min}$ & \\
\hline
\end{tabular}

using site-specific mutagenesis of the wild type CYP3A5pYES2/CT gene (18). The present study screened for positive clones and extracted the recombinant plasmid of CYP3A5 gene polymorphism expression vectors. The recombinant plasmid was transformed into Saccharomyces cerevisiae INVSc1 (19). The transformants were selected on Schaeffer's-glucose agar plates at $30^{\circ} \mathrm{C}$ for $2-4$ days. The microsomal CYP3A5 yeast protein was extracted, western blotting was performed as described previously (20). The microsomal CYP3A5 yeast proteins were separated on SDS polyacrylamide gels. Proteins were probed with the anti his-V5 (Santa Cruz Biotechnology,
Inc., Dallas, TX, USA). The blots were scanned with an Odyssey imager (LI-COR Biosciences, Lincoln, NE, USA).

An in vitro study of amlodipine metabolism by CYP3A5 recombinant enzymes. A primary stock solution of amlodipine was prepared in $50 \%$ methanol at a concentration of $100 \mu \mathrm{g} / \mathrm{ml}$. Estazolam (Beijing Yimin Pharmaceutical Co., Ltd., Beijing, China) was prepared from the primary stock at a concentration of $0.4 \mu \mathrm{g} / \mathrm{ml}$ for use as an internal standard. Working standard solutions of amlodipine were prepared from the primary stock at concentrations of 100, 50, $25,12.5,5.25,3.125,1.5625$ and $0.78125 \mathrm{ng} / \mathrm{ml}$. All solutions were stored at $4^{\circ} \mathrm{C}$ and warmed to room temperature before use. The constructed CYP3A5 gene polymorphism systems were used to metabolize amlodipine. The amount of drug metabolized was detected using LC-MS and HPLC as previously described (15). Amlodipine solution (50 $\mu \mathrm{l})$, internal standard $(50 \mu \mathrm{l}), 500 \mu \mathrm{l}$ blank serum $(500 \mu \mathrm{l})$ and $1 \mathrm{M}$ sodium hydroxide $(200 \mu \mathrm{l})$ were added to $1.5 \mathrm{ml}$ methyl tert-butyl ether. Following vortexing and centrifugation at a speed of $1,000 \times \mathrm{g}$ at $4^{\circ} \mathrm{C}$ for $10 \mathrm{~min}$, the organic phase was dried at $45^{\circ} \mathrm{C}$ under nitrogen, reconstituted in methanol $(80 \%, 200 \mu \mathrm{l})$ and injected onto a Phenomenex Luna column C18 (150x2 mm; Phenomenex, Inc., Torrance, CA, USA). The mobile phase consisted of methanol ( $0.1 \%$ methanoic acid $)$ and $1 \mathrm{M}$ ammonium acetate $(0.1 \%$ methanoic acid; methanol/ammonium acetate, 4/1) with a flow rate of $0.2 \mathrm{ml} / \mathrm{min}$. A standard curve was fitted using standard concentrations for the $\mathrm{X}$-axis and the area ratio of standard/internal standard for the Y-axis. Values for the rate of metabolite formation from $0.2 \mathrm{mg} / \mathrm{ml}$ of the recombinant enzyme were derived using the standard curve. $\mathrm{K}_{\mathrm{m}}, \mathrm{V}_{\max }$ and $\mathrm{V}_{\max } / \mathrm{K}_{\mathrm{m}}$ values were determined using GraphPad Prism 5.0 (GraphPad Software, Inc., La Jolla, CA, USA) and the Michaelis-Menten equation $(6,21)$.

Statistical analysis. Values are presented as the mean \pm standard deviation. Statistical comparisons were performed using one-way analysis of variance followed by the Newman-Keuls test (GraphPad Prism 5.0; GraphPad Software, Inc.). P<0.05 was considered to indicate a statistically significant difference.

\section{Results}

Differences in amlodipine PD among CYP3A5 gene polymorphisms. The present study assessed the genotype of 57 hypertensive patients from the Health Management Center of the Third Xiangya Hospital. The number of patients with each polymorphism were as follows: CYP3A $5^{*} 1 /^{*} 1$ in 7 patients $(12.3 \%)$; CYP3A5 $5^{*} 1 /^{*} 3$ in 28 patients $(49.1 \%)$; CYP3A $5 * 4$ in 2 patients $(3.5 \%)$; and CYP3A $5^{*} 6$ in 2 patients $(3.5 \%)$. The mean age of the patients (26 males and 13 females) was $45.61 \pm 2.33$ years and the mean body mass index was $24.15 \pm 1.46$. Change in blood pressure prior to and following treatment with amlodipine was also recorded (Table IV). Following administration of amlodipine, blood pressure in all patients decreased. The magnitude of the change in blood pressure varied among patients. Individuals with the CYP $3 A 5^{*} 1 /{ }^{*} 3$ polymorphism exhibited the highest change in blood pressure, followed by CYP3A $5^{*} 4, \mathrm{CYP} 3 \mathrm{~A} 5^{*} 1 /^{*} 1$, and CYP3A5*6 (Fig. 1A). 
Table IV. Antihypertensive effects of CYP3A5 gene polymorphisms.

\begin{tabular}{|c|c|c|c|c|c|c|c|}
\hline \multirow[b]{2}{*}{ Polymorphism } & \multirow[b]{2}{*}{$\begin{array}{c}\text { Number of } \\
\text { patients }\end{array}$} & \multicolumn{3}{|c|}{ Systolic BP (mmHg) } & \multicolumn{3}{|c|}{ Diastolic BP (mmHg) } \\
\hline & & $\begin{array}{c}\text { Prior to } \\
\text { amlodipine } \\
\text { administration }\end{array}$ & $\begin{array}{c}\text { Following } \\
\text { amlodipine } \\
\text { administration }\end{array}$ & Difference & $\begin{array}{c}\text { Prior to } \\
\text { amlodipine } \\
\text { administration }\end{array}$ & $\begin{array}{c}\text { Following } \\
\text { amlodipine } \\
\text { administration }\end{array}$ & Difference \\
\hline CYP3A5*1/"1 & 7 & $145.21 \pm 19.4$ & $137.54 \pm 17.0$ & $7.67 \pm 3.2$ & $92.94 \pm 12.4$ & $88.18 \pm 11.3$ & $4.76 \pm 2.5$ \\
\hline CYP3A5*1/3 3 & 28 & $144.67 \pm 17.6$ & $127.41 \pm 8.3$ & $17.27 \pm 6.7^{\mathrm{a}}$ & $89.53 \pm 12.6$ & $78.27 \pm 5.9$ & $11.27 \pm 81.4^{a}$ \\
\hline CYP3A5*4 & 2 & $156.26 \pm 19.3$ & $141.16 \pm 17.9$ & $15.53 \pm 10.4^{\mathrm{a}}$ & $94.17 \pm 12.2$ & $84.93 \pm 12.3$ & $9.83 \pm 5.9^{\mathrm{a}}$ \\
\hline CYP3A5*6 & 2 & $150.29 \pm 13.4$ & $143.81 \pm 13.1$ & $6.48 \pm 4.7^{\mathrm{b}}$ & $93.03 \pm 11.4$ & $89.52 \pm 11.9$ & $3.51 \pm 3.4^{\mathrm{b}}$ \\
\hline
\end{tabular}

${ }^{\mathrm{a}} \mathrm{P}<0.05$ vs. CYP3A $5 * 1 /{ }^{*} 1$ group; ${ }^{\mathrm{b}} \mathrm{P}>0.1$ vs. CYP3A $5 * 1 /{ }^{*} 1$ group. Data are presented as the mean \pm standard deviation. CYP3A5, cytochrome P450 3A5; BP, blood pressure.

In vivo drug metabolism of amlodipine. The differences in amlodipine PK among different $C Y P 3 A 5$ gene polymorphisms were compared. As presented in Table V, CYP3A5 recombinant enzymes influenced the PK of amlodipine in hypertensive patients. There were differences in the metabolic rate among the polymorphisms; individuals with the CYP3A5*6 polymorphism exhibited the highest metabolic ratio of amlodipine, followed by $C Y P 3 A 5^{*} 1 /^{*} 1, C Y P 3 A 5^{*} 4$ and $C Y P 3 A 5^{*} 1 /^{*} 3$. Compared with $C Y P 3 A 5^{*} 1 I^{*} l$, there were significant differences in $C Y P 3 A 5^{*} 1 /^{*} 3$ and $C Y P 3 A 5^{*} 4(\mathrm{P}<0.05)$. There was no statistically significant difference between $C Y P 3 A 5^{*} 6$ and CYP3A5 $1 / /^{*} 1$ ( $\mathrm{P}=0.5$; Fig. 1B). These results may explain the differences in the antihypertensive effect of amlodipine in individuals with different $C Y P 3 A 5$ polymorphisms.

Construction and verification of the Saccharomyces cerevisiae expression system for CYP3A5 gene polymorphisms. CYP3A5 gene polymorphism expression vectors were successfully constructed for CYP3A $5^{*} 1 /^{*} 1$, CYP $3 A 5^{*} 4$ and CYP3A5*6, however, this was not achieved for CYP3A*1/*3. The site-specific mutagenesis failed in the CYP $3 \mathrm{~A} 5^{*} 1 /{ }^{*} 3$ mutation as the CYP3A 5*1/"3 mutation occurs in the CYP3A5 gene intron. The introduction of the nucleotides required to form each CYP3A5 polymorphism was confirmed with a PCR electrophoretogram (Fig. 2A). Expression vectors constructed by the PCR method were used as a template for PCR amplification. PCR amplification products were subjected to agarose gel electrophoresis. In addition, agarose gel electrophoresis was performed to analyze the constructed expression vector. The results demonstrated that the expression vector was successfully constructed (Fig. 2B). Double digestion of the expression vectors was performed to further confirm that the expression vectors were correct. The digestion products were assessed using agarose gel electrophoresis. The results demonstrated that the expression vectors were successfully constructed (Fig. 2C). Additionally, Saccharomyces cerevisiae formed into monoclonal cells, indicating that the CYP3A5 gene polymorphism expression vectors were successfully transformed into the INVSC1 yeast cells (Fig. 2D). Bidirectional sequencing comparisons were performed using positive bacterial clones of the double digestion vectors (Fig. 3). CYP3A $5 * 4$, the constructed gene fragment exhibited a base group mutation
Table V. Amlodipine metabolic ratio of CYP3A5 gene polymorphisms.

\begin{tabular}{lcc}
\hline Polymorphism & $\begin{array}{c}\text { Number of } \\
\text { patients }\end{array}$ & $\begin{array}{c}\mathrm{V} \text { max } \\
(\mathrm{ng} / \mathrm{ml} / \mathrm{min})\end{array}$ \\
\hline CYP3A5 $^{*} 1 /^{*} 1$ & 7 & $0.6727 \pm 0.028$ \\
CYP3A5 $^{*} 1 /^{*} 3$ & 28 & $0.2584 \pm 0.013^{\mathrm{a}}$ \\
CYP3A5 $4^{*}$ & 2 & $0.3347 \pm 0.029^{\mathrm{a}}$ \\
CYP3A5 $^{*} 6$ & 2 & $0.7174 \pm 0.053$
\end{tabular}

Data are presented as the mean \pm standard deviation. ${ }^{\mathrm{a}} \mathrm{P}<0.05$ vs. CYP3A5*1/*1. CYP3A5, cytochrome P450 3A5.

from A to $\mathrm{G}$ at bp 599, without the presence of other mutations, indicating that the fragment was CYP3A5*4. CYP3A $5 * 6$, the constructed gene fragment exhibited base group mutation from $\mathrm{G}$ to $\mathrm{A}$ at bp 624, without the presence of other mutations, indicating that the fragment was CYP3A $5^{*} 6$. The results demonstrated that the present study successfully constructed recombinant yeast expression systems for three single nucleotide mutants of human cytochrome CYP3A5, including CYP3A5 $1 /{ }^{*} 1$, CYP3A5*4 and CYP3A5 6 . No additional mutations, apart from the desired point mutations created in the expression vectors, were identified. The gene sequencing results demonstrated that there were mutations in the required base locus while other bases were normal (Fig. 3A-C). These results confirmed that the CYP3A5 gene polymorphism vectors were successfully constructed.

PK prediction model for CYP3A5 gene polymorphisms. To assess the effects of CYP3A5 gene polymorphisms on drug metabolism, the present study constructed a PK prediction model by expressing CYP3A5 gene polymorphism vectors in Saccharomyces cerevisiae. After the CYP3A5 gene polymorphism expression vectors were transformed into yeast, the transformants were selected on Schaeffer's-glucose agar plates. Subsequently, western blotting was performed to detect protein expression. The results (Fig. 3D) demonstrated that CYP3A5 ${ }^{*} 1 /^{*} 1$ and CYP3A5 6 proteins were detected 
A

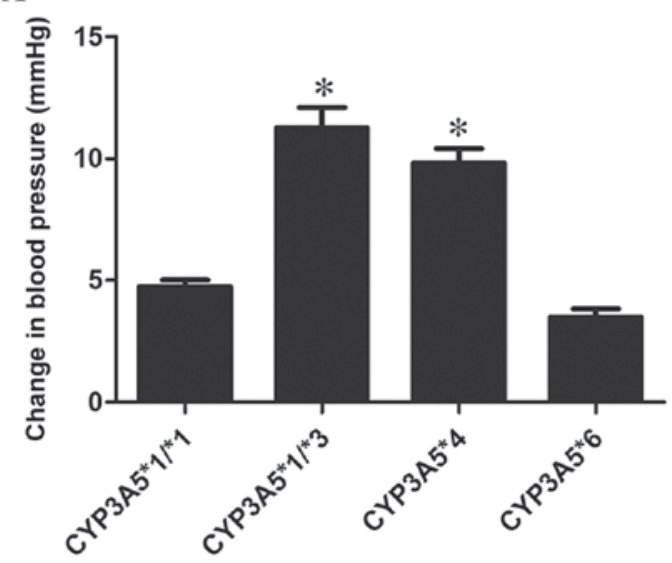

B

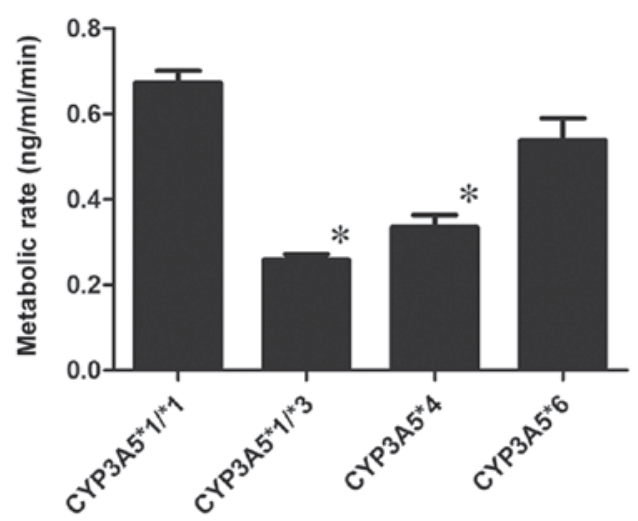

Figure 1. In vivo drug metabolism of amlodipine. (A) The antihypertensive effects of amlodipine for each CYP3A5 gene polymorphism. (B) Amlodipine metabolism ratio for each CYP3A5 gene polymorphism. Data are presented as the mean + standard deviation. ${ }^{*} \mathrm{P}<0.05$ vs. the CYP3A5*1/* 1 group. CYP3A5, cytochrome P450 3A5.

A

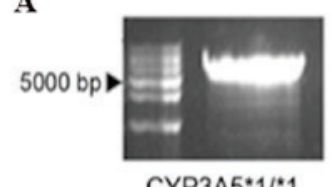

CYP 3 A $5 * 1 / * 1$

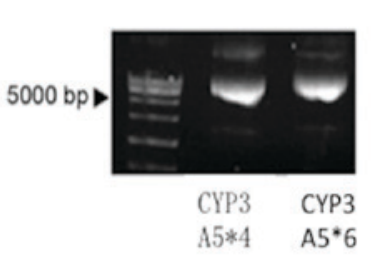

D

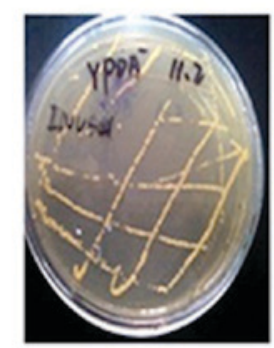

Saccharomyces cerevisiae INVSc1
B

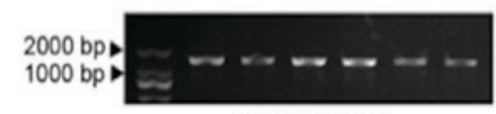

CYP 3 A $5 * 1 / * 1$

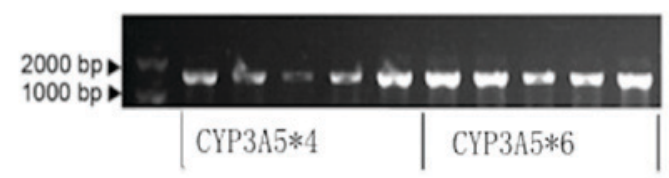

CYP 3 A5*6

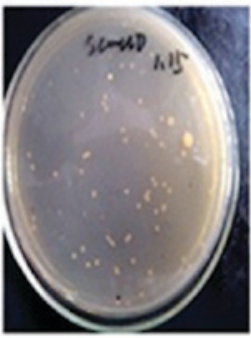

CYP 3 A5*1/*1 transformant

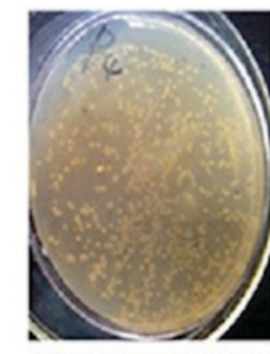

CYP $3 A 5^{*} 4$ transformant
C

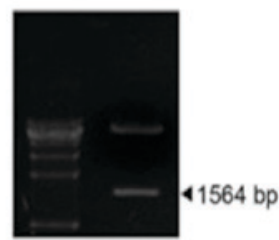

CYP 3 A $5 * 1 / * 1$

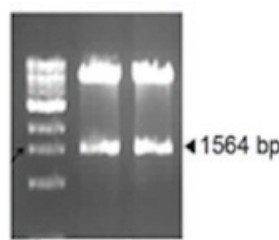

CYP3 CYP3

A5*4 A5*6

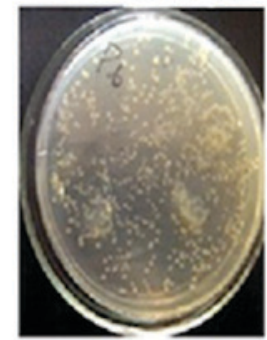

CYP 3 A5 6 transformant

Figure 2. Construction and verification of Saccharomyces cerevisiae expression. systems for CYP3A5 gene polymorphisms. (A) Electrophoretogram of expression plasmids for the $C Y P 3 A 5$ gene polymorphisms. (B) Polymerase chain reaction results of $C Y P 3 A 5^{*} 1 /^{*} 1, C Y P 3 A 5^{*} 4$ and $C Y P 3 A 5^{*} 6$ expression vector transformation. (C) Electrophoretogram of double digests of the expression vector. (D) Saccharomyces cerevisiae INVSc1 and the transformants of different CYP3A5 alleles. CYP3A5, cytochrome P450 3A5; WT, wildtype.

at $54 \mathrm{kDa}$; whereas $\mathrm{CYP} 3 \mathrm{~A} 5{ }^{*} 4$ was detected at $18 \mathrm{kDa}$. These results demonstrate that the CYP3A5 gene polymorphism sequences were successfully transformed into the Saccharomyces cerevisiae expression vectors.

In vitro drug metabolism of amlodipine by CYP3A5 recombinant enzymes. The standard curve was fitted using standard concentrations for the $\mathrm{X}$-axis and the area ratio of standard/internal standard for the Y-axis (Fig. 4A and B).
Values for the rate of metabolite formation using $0.2 \mathrm{mg} / \mathrm{ml}$ of the recombinant enzymes were derived using the standard curve. The $\mathrm{V}_{\max }$ of amlodipine metabolized by CYP3A5 $1 /^{*} 1$, CYP3A5*4 and CYP3A5*6 was $0.61 \pm 0.02,0.42 \pm 0.02$ and $0.66 \pm 0.04 \mathrm{pmol} / \mathrm{min} / \mathrm{pmol} \mathrm{P} 450$, respectively. The $\mathrm{K}_{\mathrm{m}}$ of CYP3A5*1/*1, CYP3A5*4 and CYP3A5*6 was $0.32 \pm 0.12 \mu \mathrm{mol} / 1,0.31 \pm 0.05 \mu \mathrm{mol} / 1$ and $0.32 \pm 0.08 \mu \mathrm{mol} / 1$, respectively. The drug clearance $\left(\mathrm{V}_{\max } / \mathrm{K}_{\mathrm{m}}\right)$ for CYP3A $5^{*} 1 /^{*} 1$, CYP3A $5^{*} 4$ and CYP3A5 6 was $1.91 \pm 0.05,1.35 \pm 0.15$ and 
A

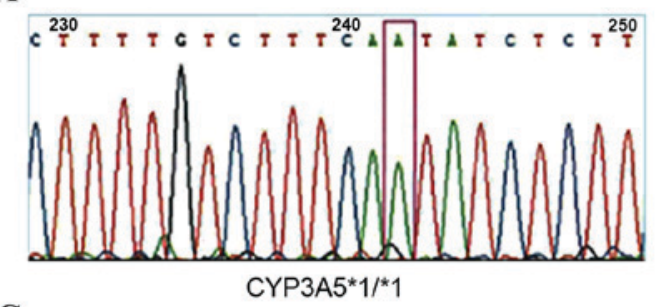

C

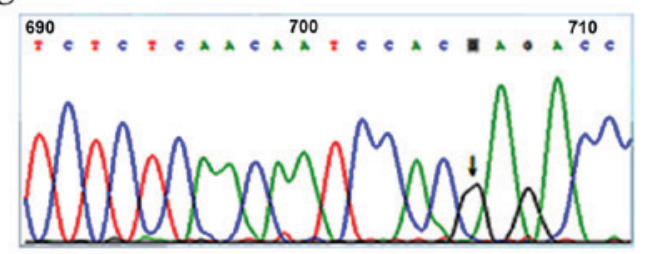

CYP3A5*4 $(A \rightarrow G)$

B

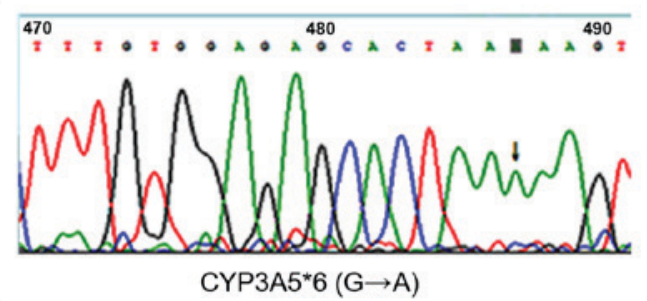

D

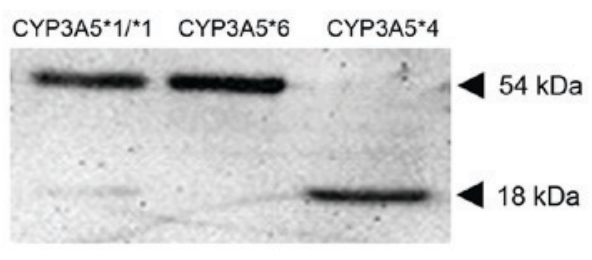

Figure 3. The pharmacokinetic prediction model for CYP3A5 gene polymorphisms. Gene sequencing results of (A) $C Y P 3 A 5^{*} 1 /^{*} 1,(\mathrm{~B})$ CYP3A5 6 and (C) CYP3A5*4. (D) Western blot analysis results of the microsomal protein expression of the Saccharomyces cerevisiae gene polymorphisms CYP3A5"1/"1, CYP3A5*4 and CYP3A5*6. CYP3A5, cytochrome P450 3A5.

A

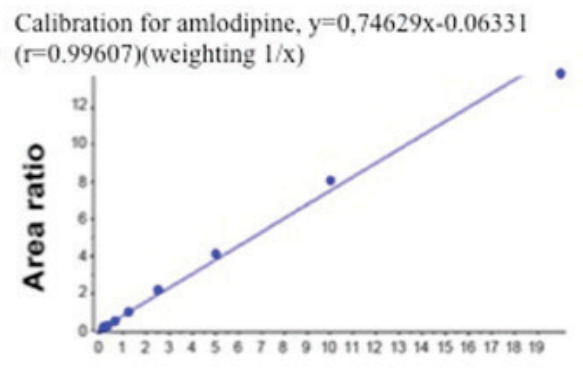

Concentration ratio
B

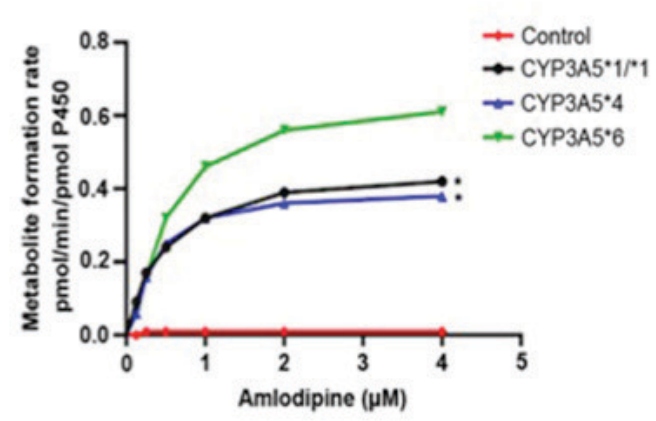

C

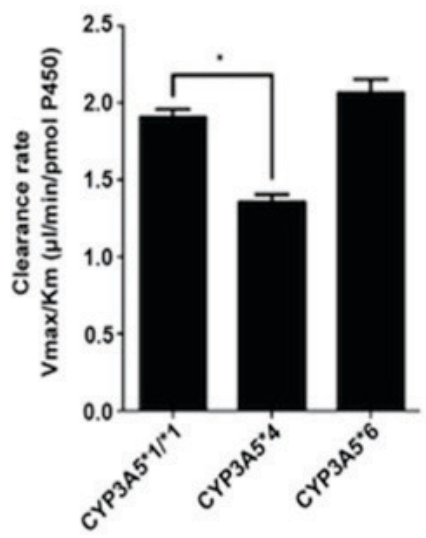

Figure 4. Pharmacokinetics of amlodipine metabolized by CYP3A5 recombinant enzymes. (A) Standard curve of amlodipine metabolism. (B) Michaelis-Menten graph of amlodipine metabolism by CYP3A5 recombinant enzymes. (C) Amlodipine clearance by CYP3A5 recombinant enzymes. Data are presented as the mean \pm standard deviation. ${ }^{*} \mathrm{P}<0.05$ vs. the CYP3A5*1/*1 group. CYP3A5, cytochrome P450 3A5.

$2.06 \pm 0.05 \mu \mathrm{l} / \mathrm{min} / \mathrm{pmol} \mathrm{P} 450$, respectively (Fig. 4C). The results demonstrated that CYP3A5 recombinant enzymes influenced the PK of amlodipine. There was a significant difference in the drug clearance between CYP3A $5^{*} 4$ and CYP3A5*1/*1 $(\mathrm{P}<0.05)$. The difference between CYP3A5*6 and CYP3A $5^{*} 1 /^{*} 1$ was not statistically significant $(\mathrm{P}>0.05)$.

\section{Discussion}

CYP3A5 has an important role in the metabolism of various drugs. The major polymorphisms of $C Y P 3 A 5$ are $C Y P 3 A 5^{*} 1, C Y P 3 A 5^{*} 2, C Y P 3 A 5^{*} 3, C Y P 3 A 5^{*} 4, C Y P 3 A 5^{*} 6$ and $C Y P 3 A 5^{*} 7(22,23)$. Previous studies have reported the successful construction of an in vitro Saccharomyces cerevisiae expression systems for $C Y P 3 A 4, C Y P 2 D 6$ and $C Y P 2 C 9(22,24)$. To the best of our knowledge, the present study is the first to construct the in vitro CYP3A5 gene polymorphism Saccharomyces cerevisiae expression systems for $C Y P 3 A 5^{*} 1 /^{*} 1, C Y P 3 A 5^{*} 4$ and $C Y P 3 A 5^{*} 6$, and to compare the in vitro metabolic rate with in vivo rates.
Amlodipine is a $C Y P 3 A 5$ substrate that is widely used for the treatment of hypertension. Numerous studies have demonstrated that the CYP3A5 gene polymorphisms affect the $\mathrm{PK}$ and $\mathrm{PD}$ of amlodipine (24-27). The in vitro drug metabolism results of amlodipine by $C Y P 3 A 5$ recombinase in the present study demonstrated that there were significant differences between $C Y P 3 A 5^{*} 4$ and $C Y P 3 A 5^{*} 1 /^{*} 1$ (CYP $3 A 5^{*} 1 /^{*} 1>C Y P 3 A 5^{*} 6>$ $\left.C Y P 3 A 5^{*} 4\right)$, while the in vivo $\mathrm{PK}$ results for amlodipine demonstrated that $C Y P 3 A 5^{*} 6$ exhibited the highest metabolic ratio of amlodipine, followed by $C Y P 3 A 5^{*} 1 /^{*} 1$ and $C Y P 3 A 5^{*} 4$. There was a significant difference between the in vitro and in vivo PK results obtained for $C Y P 3 A 5^{*} 1 /^{*} 1$ and $C Y P 3 A 5^{*} 4(\mathrm{P}<0.05)$ however no significant difference between $C Y P 3 A 5^{*} 1 /^{*} 1$ and CYP3A5*6.

The reaction ratio of in vivo $C Y P 3 A 5^{*} 6$ was much larger compared with $C Y P 3 A 5^{*} 1 /^{*} 1$ and $C Y P 3 A 5^{*} 4$ polymorphisms, which is in contrast to the in vitro drug metabolism results. This may be due to the fact that there were 2 patients $(3.51 \%)$ with the $C Y P 3 A 5^{*} 6$ allele, which is higher than the normal $C Y P 3 A 5^{*} 6$ allele frequency. The $C Y P 3 A 5^{*} 1$ allele frequency 
is $25 \%$ in Chinese populations, and the $C Y P 3 A 5^{*} 3$ allele frequency is $>25 \%$. However, the $C Y P 3 A 5^{*} 6$ allele is not as common in Asian populations, including Chinese and Japanese populations (5,28-30). Further studies that focus on the mechanisms and frequency of the $C Y P 3 A 5^{*} 6$ allele are required. Large clinical trials should be conducted to clarify the difference between the PK effects of these three gene polymorphisms. The antihypertensive effects of amlodipine among different patients were determined. $C Y P 3 A 5^{*} 1 /^{*} 3$ exhibited the largest antihypertensive effect, followed by $C Y P 3 A 5^{*} 4$, $C Y P 3 A 5^{*} 1 /^{*} 1$ and $C Y P 3 A 5^{*} 6$. The in vivo PK data demonstrated that $C Y P 3 A 5^{*} 1 /^{*} 1$ had the largest reaction ratio. Thus, the antihypertensive results are consistent with the PK results. The current study had certain limitations that must be stated. The current study failed to construct the in vitro $C Y P 3 A 5^{*} 1^{*} 3$ polymorphism Saccharomyces cerevisiae expression vector as the $C Y P 3 A 5^{*} 1 /^{*} 3$ mutation occurs in the $C Y P 3 A 5$ gene intron and it was difficult to mutate the intron. In future studies, we hope to identify another method to solve this problem. Additionally, only 2 patients were included in $C Y P 3 A 5^{*} 4$ and $C Y P 3 A 5^{*} 6$ groups, and the small patient population and the retrospective nature of the study do not allow any conclusions to be drawn about the effectiveness of this prediction method. Studies consisting of larger groups of patients with long-term follow-up are required to confirm these results.

In conclusion, the present study indicates that the CYP $3 A 5$ gene polymorphism Saccharomyces cerevisiae expression system is a potential tool for the prediction of drug metabolism, particularly for novel drugs prior to their application in clinical trials. This expression system may also aid in the development of individualized clinical medications.

\section{Acknowledgements}

This study was supported by grants from the National Science and Technology Major Projects for 'Major New Drugs Innovation and Development' (grant no. 2012ZX09303014001), the National Natural Science Foundation of China (grant no. 81273594) and Fundamental Research Funds for the Central Universities of Central South University (grant no. 2016zzts153).

\section{References}

1. Emoto C and Iwasaki K: Approach to predict the contribution of cytochrome P450 enzymes to drug metabolism in the early drug-discovery stage: The effect of the expression of cytochrome $\mathrm{b}(5)$ with recombinant $\mathrm{P} 450$ enzymes. Xenobiotica 37 : 986-999, 2007.

2. Zhang YP, Zuo XC, Huang ZJ, Cai JJ, Wen J, Duan DD and Yuan H: CYP3A5 polymorphism, amlodipine and hypertension. J Hum Hypertens 28: 145-149, 2014.

3. Lin YS, Dowling AL, Quigley SD, Farin FM, Zhang J, Lamba J, Schuetz EG and Thummel KE: Co-regulation of CYP3A4 and CYP3A5 and contribution to hepatic and intestinal midazolam metabolism. Mol Pharmacol 62: 162-172, 2002.

4. Shin J, Pauly DF, Pacanowski MA, Langaee T, Frye RF and Johnson JA: Effect of cytochrome P450 3A5 genotype on atorvastatin pharmacokinetics and its interaction with clarithromycin. Pharmacotherapy 31: 942-950, 2011.

5. Kuehl P, Zhang J, Lin Y, Lamba J, Assem M, Schuetz J, Watkins PB, Daly A, Wrighton SA, Hall SD, et al: Sequence diversity in CYP3A promoters and characterization of the genetic basis of polymorphic CYP3A5 expression. Nat Genet 27 : 383-391, 2001
6. Williams JA, Ring BJ, Cantrell VE, Jones DR, Eckstein J, Ruterbories K, Hamman MA, Hall SD and Wrighton SA: Comparative metabolic capabilities of CYP3A4, CYP3A5, and CYP3A7. Drug Metab Dispos 30: 883-891, 2002.

7. Walker DK, Humphrey MJ and Smith DA: Importance of metabolic stability and hepatic distribution to the pharmacokinetic profile of amlodipine. Xenobiotica 24: 243-250, 1994.

8. Sugimoto K, Uno T and Tateishi T: Effects of the CYP3A5 genotype on omeprazole sulfoxidation in CYP2C19 PMs. Eur J Clin Pharmacol 64: 583-587, 2008.

9. Kim KA, Park PW, Lee OJ, Choi SH, Min BH, Shin KH, Chun BG, Shin JG and Park JY: Effect of CYP3A5*3 genotype on the pharmacokinetics and pharmacodynamics of amlodipine in healthy Korean subjects. Clin Pharmacol Ther 80: 646-656, 2006.

10. Elmachad M, Elkabbaj D, Elkerch F, Laarabi FZ, Barkat A, Oualim Z and Sefiani A: Frequencies of CYP3A $5^{*} 1 /^{*} 3$ variants in a Moroccan population and effect on tacrolimus daily dose requirements in renal transplant patients. Genet Test Mol Biomarkers 16: 644-647, 2012.

11. Provenzani A, Notarbartolo M, Labbozzetta M, Poma P, Vizzini G, Salis P, Caccamo C, Bertani T, Palazzo U, Polidori P, et al: Influence of $C Y P 3 A 5$ and $A B C B 1$ gene polymorphisms and other factors on tacrolimus dosing in Caucasian liver and kidney transplant patients. Int J Mol Med 28: 1093-1102, 2011

12. Amundsen R, Åsberg A, Ohm IK and Christensen $\mathrm{H}$ : Cyclosporine A- and tacrolimus-mediated inhibition of CYP3A4 and CYP3A5 in vitro. Drug Metab Dispos 40: 655-661, 2012.

13. Guo C, Pei QI, Tan H, Huang Z, Yuan H and Yang G: Effects of genetic factors on the pharmacokinetics and pharmacodynamics of amlodipine in primary hypertensive patients. Biomed Rep 3: 195-200, 2015.

14. Choi M, Eren-Dogu ZF, Colangelo C, Cottrell J, Hoopmann MR, Kapp EA, Kim S, Lam H, Neubert TA, Palmblad M, et al: ABRF proteome informatics research group (iPRG) 2015 study: Detection of differentially abundant proteins in label-free quantitative LC-MS/MS experiments. J Proteome Res Jan 3, 2017 (Epub ahead of print).

15. Beresford AP, Macrae PV, Alker D and Kobylecki RJ: Biotransformation of amlodipine. Identification and synthesis of metabolites found in rat, dog and human urine/confirmation of structures by gas chromatography-mass spectrometry and liquid chromatography-mass spectrometry. Arzneimittelforschung 39: 201-209, 1989

16. Chennuru LN, Choppari T, Nandula RP, Zhang T and Franco P: Direct separation of pregabalin enantiomers using a zwitterionic chiral selector by high performance liquid chromatography coupled to mass spectrometry and ultraviolet detection. Molecules 21: E1578, 2016.

17. Colson CA, Cornelis PE, Digneffe CS and Walon C: Genetically engineered microorganisms for massive production of amylolytic enzymes and process for preparing same. US Patend $4469791 \mathrm{~A}$. Filed February 13, 1981; issued September 4, 1984.

18. Narita V, Widyanto RM, Pambudi S and Sudiro TM: Cloning of dengue virus type 3 (Indonesian Strain D3-1703) non structural-1 gene into pYES2/CT vector. Makara Sains 15: 173-178, 2011.

19. Costa IM, Schultz L, de Araujo Bianchi Pedra B, Leite MS, Farsky SH, de Oliveira MA, Pessoa A and Monteiro G: Recombinant L-asparaginase 1 from Saccharomyces cerevisiae: An allosteric enzyme with antineoplastic activity. Sci Rep 6: 36239, 2016.

20. Huang Y, Liu XL, Wen J, Huang LH, Lu Y, Miao RJ, Liu X, Li Y, Xing XW and Yuan H: Downregulation of the $\beta 1$ adrenergic receptor in the myocardium results in insensitivity to metoprolol and reduces blood pressure in spontaneously hypertensive rats. Mol Med Rep 15: 703-711, 2017.

21. Guengerich FP, Brian WR, Iwasaki M, Sari MA, Bäärnhielm C and Berntsson P: Oxidation of dihydropyridine calcium channel blockers and analogues by human liver cytochrome P-450 IIIA4. J Med Chem 34: 1838-1844, 1991.

22. Ha HR, Chen J, Freiburghaus AU and Follath F: Metabolism of theophylline by cDNA-expressed human cytochromes $\mathrm{P}-450 . \mathrm{Br}$ J Clin Pharmacol 39: 321-326, 1995.

23. Ho H, Pinto A, Hall SD, Flockhart DA, Li L, Skaar TC, Cadman P, O'Connor DT, Wagner U, Fineberg NS and Weinberger MH: Association between the CYP3A5 genotype and blood pressure. Hypertension 45: 294-298, 2005. 
24. Granvil CP, Yu AM, Elizondo G, Akiyama TE, Cheung C, Feigenbaum L, Krausz KW and Gonzalez FJ: Expression of the human CYP3A4 gene in the small intestine of transgenic mice: In vitro metabolism and pharmacokinetics of midazolam. Drug Metab Dispos 31: 548-558, 2003.

25. Zhang L, Miyaki K, Wang W and Muramatsu M: CYP3A5 polymorphism and sensitivity of blood pressure to dietary salt in Japanese men. J Hum Hypertens 24: 345-350, 2010.

26. Stopher DA, Beresford AP, Macrae PV and Humphrey MJ: The metabolism and pharmacokinetics of amlodipine in humans and animals. J Cardiovasc Pharmacol 12 (Suppl 7): S55-S59, 1988.

27. Faulkner JK, McGibney D, Chasseaud LF, Perry JL and Taylor IW: The pharmacokinetics of amlodipine in healthy volunteers after single intravenous and oral doses and after 14 repeated oral doses given once daily. Br J Clin Pharmacol 22 21-25, 1986.
28. Balram C, Zhou Q, Cheung YB and Lee EJ: CYP3A5*3 and *6 single nucleotide polymorphisms in three distinct Asian populations. Eur J Clin Pharmacol 59: 123-126, 2003.

29. Fukuen S, Fukuda T, Maune H, Ikenaga Y, Yamamoto I, Inaba T and Azuma J: Novel detection assay by PCR-RFLP and frequency of the CYP3A 5 SNPs, CYP $3 A 5^{*} 3$ and *6, in a Japanese population. Pharmacogenetics 12: 331-334, 2002.

30. Thompson EE, Kuttab-Boulos H, Witonsky D, Yang L, Roe BA and Di Rienzo A: CYP3A variation and the evolution of salt-sensitivity variants. Am J Hum Genet 75: 1059-1069, 2004. 